\title{
DEBATE CONTEMPORÂNEO: GEOGRAFIAS OU GEOGRAFIA? FRAGMENTAÇÃO OU TOTALIZAÇÃO?
}

\author{
Dirce Maria Antunes Suertegaray* \\ Universidade Federal do Rio Grande do Sul**
}

Resumo: Este artigo é resultado, inicialmente, de uma classificação temática da Geografia brasileira. A diversidade temática revelada nesse levantamento inicial permitiu na continuidade uma reflexão sobre fragmentação e totalidade/ totalização em Geografia como dimensões presentes no debate contemporâneo deste campo do conhecimento. A fragmentação geográfica se expressa em diferentes temas e no conceito de espaço geográfico. A análise é direcionada para a necessidade de avançar a discussão e a busca da unidade na Geografia.

Palavras-chave: Geografia. Fragmentação. Totalidade/totalização.

\section{Contemporary question: Geographies or Geography? Fragmentation or totalization?}

Abstract: This article is the result of a thematic classification of Brazilian Geography. The thematic diversity revealed in this initial survey allowed a reflection on fragmentation and totality/totalization in Geography as dimensions presents in the contemporary debate of this field of knowledge. Geographical fragmentation is expressed in different themes and in the concept of geographic space. The analysis is directed to the need to advance the discussion and the search for unity in Geography.

Keyboards: Geography. Fragmentation. Totality/totalization.

\section{Debate contemporáneo: Geografías o Geografía? Fragmentación o totalização?}

Resumen: Se trata de este artículo de un estudio preliminar sobre la diversidad de la Geografía brasileña. La diversidad temática revelada en ese levantamiento inicial, permitió en la continuidad una reflexión sobre fragmentación y totalización en Geografía como dimensiones presentes en el debate contemporáneo, en este campo del conocimiento. La fragmentación geográfica se expresa en diferentes temas y en el concepto de espacio geográfico. El análisis exprime la necesidad de avanzar la discusión y la búsqueda de la unidad en la Geografía.

Palabras claves: Geografía. Fragmentación. Totalización. 


\section{Introdução}

Este texto foi construído a partir de uma solicitação inicial. Naquele momento, XI ENANPEGE (2015), a solicitação era de que fosse feita uma reflexão sobre a diversidade da Geografia brasileira. Esse trabalho gerou um levantamento que, mesmo não tendo sido exaustivo, ou seja, não correspondendo ao universo da Geografia brasileira, permitiu perceber a diversidade de temas em análise pelos geógrafos no Brasil. A primeira leitura expressa uma sistematização num contexto classificatório que, por ser classificatório, é questionável. Entretanto, serviu para reflexões posteriores.

Num segundo momento utilizamos essa reflexão inicial para pensar sobre fragmentação e totalização, realizada, com outros títulos, em palestras que participei em diferentes lugares do país, a exemplo das falas $O$ que significa pensar geograficamente o mundo hoje? Na UFPA; Perspectiva da Geografia para o século XXI no Brasil na FUFRG e, finalmente palestras que já expressaram o texto aqui escrito: Debate contemporâneo Geografias ou Geografia? Fragmentação ou Totalização? Na UFJF, na UERJ Campus de São Gonçalo e na UFF.

Neste processo formula-se algumas ideias sobre fragmentação e totalização em Geografia, na medida em que, na atualidade, essa discussão é um pouco velada, muito embora esteja presente no debate em pequenos grupos, aos quais tenho alcance.

\section{Fragmentação e Totalização}

A pergunta colocada como título deste artigo remete a uma reflexão sobre a Geografia enquanto campo do conhecimento. Nesse sentido considero relevante indagar: qual é a concepção de Geografia presente em nossos dias? Há uma discussão latente na Geografia, hoje, que induz a pensar sobre compartimentação, fragmentação e/ou totalidade. Aqui optamos por falar de fragmentação e totalização entendendo-os enquanto processos, o primeiro de ruptura, parcelamento, e o segundo de articulação, contextualização.

Numa visão panorâmica observa-se hoje uma fragmentação da Geografia em diferentes temas, abordagens e caminhos investigativos. Há por parte de geógrafos e geógrafas nacionais e internacionais um malestar em relação ao primado da fragmentação, na medida em que esta fragmentação não permite a compreensão dos processos que fundam a nossa sociedade e que produzem o espaço geográfico.

O exemplo mais contundente dessa dificuldade vivemos hoje no Brasil, todo dia nos deparamos com inúmeros fatos e análises que buscam explicar os últimos acontecimentos vividos no país. São inúmeros os fragmentos explicativos. Como efetivamente entender a situação vivida pelos brasileiros?

Fragmentar a análise ou buscar uma explicação totalizante constitui também uma das contradições pertinentes ao campo da construção atual do conhecimento, sobretudo após o advento da chamada Pós-Modernidade, mesmo considerando a alta complexidade dessa concepção. Conforme Haesbaert (2002), o debate desse conceito se traduz em diferentes ou mesmo múltiplas possibilidades interpretativas. 0 autor, ao referir-se à difusão do termo pós-modernidade, analisa as múltiplas vertentes interpretativas e avalia que "aberta a corrida pelo imenso labirinto de definições, cada um tentava defender sua própria (pós) modernidade, de tal modo que em certos momentos elas se confundiam e, parceiros de mesmas ideias e proposições se deparavam empunhando bandeiras (rótulos) diferentes" (Haesbaert, 2002:53). 0 autor cartografa esse jogo entre intelectuais "modernos" e "pós-modernos" num quadro a partir de suas posições conservadora e crítica e do valor e amplitude com que encaram a crise (2002:54).

Acrescenta-se o já escrito em Suertegaray (2004:182):

Harvey (1993, p.47), ao discutir o tema Pós-Modernismo,
informa que este é um conceito que não pode ser
ignorado. Em seu texto, entre tantas perguntas que se
faz destacam-se: o que é o Pós-Modernismo? Uma
ruptura radical ao Modernismo? Um estilo? Uma
comercialização e domesticação do Modernismo? A
emergência de uma sociedade nova? Ou a
lógica cultural do capitalismo avançado? Este é um
tema discutido sob diferentes dimensões, cultural,
política econômica, filosófica, administrativa, entre
tantas outras. Podemos buscar o entendimento
deste conceito sob diferentes enfoques. Assim,
Pós-Modernismo pode ser entendido como uma prática
que emana da cultura do consumo de massa
enraizada na vida cotidiana nesta fase do capitalismo
avançado (Harvey, 1993, p. 65 ). Ou, como
entende Chauí (1992), um momento do capitalismo
denominado Acumulação Flexível do Capital, quando
pensado economicamente, e representado pelo
Neoliberalismo, quando nos referimos à política.

\section{A Geografia não escapou dessa circunstância.}

Para encaminhar essa discussão colocamos inicialmente alguns elementos deste embate, no campo geográfico. De um lado estão aqueles geógrafos que consideram a fragmentação como uma possibilidade analítica ampliada. De outro, estão aqueles geógrafos que consideram como fundamental a necessidade de tratar a Geografia na perspectiva totalizante. Quais as implicações de uma ou outra perspectiva?

A fragmentação e a compartimentação não são novas na ciência, a fragmentação atual e a compartimentação que foi discutida, em fases anteriores da Geografia, são 
expressões diferentes. Fragmentar é a ação de dividir em pequenas partes, quebrar em pedaços. Compartimentar é um processo que consiste em dividir um espaço, sem, necessariamente, separá-lo por completo. Pode-se "compartimentar" determinado espaço, sem deixar os "compartimentos" ausentes de relação entre si.

A compartimentação foi um processo constituinte da Geografia - seja espacial, por exemplo: o lugar (enquanto local), a região, o país, o continente para a apreensão do conhecimento geográfico, seja temática: Geografia Urbana, Agrária, Política, Econômica, Física, da População etc. Nesta perspectiva os compartimentos mantinham uma relação ou conexão entre as partes envolvidas na análise, mesmo que essas relações se dessem internamente ao espaço estudado. Ou seja, nesta perspectiva mantinha-se um dos princípios clássicos da Geografia a conexão, as relações, a especificidade dos processos atuantes no local e as formas daí decorrentes.

A compartimentação geográfica foi criticada pois mantinha as conexões no contexto de uma unidade espacial, por exemplo, a região, os estudos regionais, e não levava em conta a relação dessa com outros espaços e mesmo com processos de dimensões mais amplas, nos quais estavam incluídas - a articulação escalar como se propõe hoje.

Em contraposição a essa forma de análise discutiuse a necessidade de uma análise mais totalizante. Para a Geografia Crítica, por exemplo, a totalidade não é tudo, nem a soma das partes, a totalidade é uma associação de diferentes dimensões envolvidas na explicação de um determinado objeto de pesquisa, portanto, articulada e dialética, ou seja, está em constante processo de transformação, portanto, em processo de totalização. Diante disso optamos por fazer referência a totalização, ou seja, entender essa busca como processo, aberto ao novo e à transformação.

Certamente que essa forma de conceber o mundo e exercitar sua leitura é diferente da fragmentação e da compartimentação. Nesta abordagem a conexão entre os objetos não será feita pelo caminho da comparação e agrupamento por semelhança (forma), leva-se em conta os processos que desencadeiam a origem dos eventos, trata-se destes processos sociais, portanto, políticos, econômicos e culturais em articulação. Sem desconsiderar a dimensão da natureza, seja natural ou transfigurada.

\section{Totalidade ou Totalidades?}

Podemos também considerar que a totalidade não é necessariamente concebida de uma única maneira. No campo científico esta preocupação com a explicação ou compreensão do todo pode, a título de exemplo, ser considerada de forma diferente. Portanto, a busca da totalidade poderá ser feita sob:

a) A perspectiva sistêmica e, neste caso, o objetivo é estabelecer e/ou reconhecer basicamente a funcionalidade entre as partes envolvidas, na busca da identificação de possíveis equilíbrios ou desequilíbrios nos sistemas; buscam-se ajustes para que a ordem se estabeleça. Mesmo que nessa abordagem, sistêmico-funcionalista seja reconhecido o desequilíbrio/equilíbrio, a ordem e o caos e se admita, como na análise sistêmica contemporânea, o tempo como fundamental na transformação do sistema, a intencionalidade dessa análise é a busca do retorno ao equilíbrio ou à ordem, o padrão, como se referem os físicos. Esse equilíbrio é, no âmbito social, promovido pela ação política sustentada pelo conhecimento técnico-científico, a exemplo de muitos estudos e proposições sobre mitigações ambientais, entre outros.

Certamente que o conceito de sistema evoluiu ao longo do século $X X$ e, seja no âmbito dos estudos naturais, seja no campo social, este conceito se transformou assumindo as concepções contemporâneas da física, da química e da biologia, e é concebido a partir de uma abordagem aberta, dotada de incerteza e imprevisibilidade. Esta perspectiva, pelo menos no campo das ciências naturais, a exemplo da biologia, constitui uma superação da teoria geral dos sistemas pelas teorias de auto-organização, influenciadas pela abordagem hermenêutica expressas por Flickinger (in Flickinger e Neurer, 1994, p.34).

b) A perspectiva dialética da totalidade/totalização - nesta é necessário compreender o evento/objeto no seu contexto, sob a articulação contraditória de suas diferentes dimensões e, no seu movimento, movimento este contraditório e que se expressa numa espiral ascendente onde o conflito, a contradição, é o fundamento do movimento e da transformação. Portanto, sempre teremos mudanças, estás poderão ser para retroceder, conservar ou para transformar, mudar ...

No primeiro caso, na totalidade sistêmico-funcional em particular pode-se abstrair o movimento no tempo e considerar somente a funcionalidade de forma atemporal. No segundo, a totalidade dialética só pode ser compreendida na sua perspectiva temporal, enquanto processo, movimento.

\section{Compartimentação e/ou Fragmentação}

Se fragmentar é dividir em pedaços, as conexões são rompidas e a possibilidade de compreensão conjuntiva se torna impossível. Estaria então a Geografia tendendo para a fragmentação de seu objeto?

A história recente da Geografia nos revela distintos momentos:

$1^{\circ}$ momento: os geógrafos conceberam Geografia como a ciência da relação Homem e Natureza ou Natureza e Sociedade (ciência de síntese ou ponte).

$2^{\circ}$ momento: ciência dos estudos de Geografia Física e Geografia Humana (compartimentação). 
$3^{\circ}$ Momento: ciência da fragmentação em diferentes temas ou período do esgarçamento, ou seja, do processo de fragmentação centrado no empirismo, na visão de Marcelo Lopes de Souza (2016).

Hoje é possível verificar um acentuado grau de pluralidade temática, toma- se um exemplo, na Geografia Cultural estuda-se Cinema, Corporeidade, Cultura Visual, Cultura Caipira, Espaço Literário. Da mesma forma podemos observar essa pluralidade em outros subcampos da Geografia. A pergunta que emerge é: a pluralidade de temas promove a fragmentação? Voltaremos mais adiante a esta questão.

A fragmentação se revela não somente nos temas, também, na fragmentação do objeto da Geografia. Hoje, dependendo de temática em análise, falamos ou deixamos implícita nossa concepção do objeto da Geografia:

- Espaço natural, espaço enquanto natureza e sua dinâmica, com existência anterior à vida humana e concomitante ao homem, mas distinguido pela não existência de intencionalidade humana na sua produção.

- Espaço social, enquanto espaço produzido, vivido, concebido e representado a partir das diferentes formas de organização social. Espaços de existência e/ou, coexistência compartida, solidária, conflituosa e excludente - conceituação vinculada a Lefebvre (1985[1974]).

- Espaço vivido, enquanto espaço de expressão das vivências humanas, de suas construções materiais e/ou de suas representações.

- Espaço Geográfico como expressão da socialização, materialização e representação das relações das sociedades e das naturezas que o envolve.

- O espaço geométrico, das distâncias, das localizações, das configurações e das representações da superfície da Terra.

Ao indicarmos essas concepções de espaço vinculadas ao fazer geográfico, o que se expressa nessas diferentes construções indica, conforme Haesbaert 2017 (em interlocução durante a elaboração deste texto):

\footnotetext{
... ora um critério mais filosófico, como na distinção entre espaço vivido e espaço geométrico (ou funcional), ora um critério mais pautado pela forma de se ler a relação sociedade-natureza: espaço natural, espaço social, espaço geográfico. A base para todo este debate, como pano de fundo, seria a leitura entre espaço absoluto (geométrico, por ex.), relativo e relacional.
}

Concordamos com a referência, são essas dimensões individualizadas entre diferentes espaços (absoluto, relativo e relacional), certamente, que estão em debate na Geografia desde os anos 1970, trazidas à discussão, por exemplo, por Harvey, em seu livro "Justiça Social e a Cidade".
Nessas construções podem ser identificados diferentes saberes sobre Geografia, de um lado os geógrafos humanos, de outro os geógrafos físicos e ainda, os geógrafos- cartógrafos vinculados às geotecnologias. Então fica a pergunta impertinente, se ainda é pertinente:

Qual é o objeto ou o conceito fundante da Geografia (aquele que nos situa e ao mesmo tempo nos diferencia no campo científico)?

São mais de um os conceitos fundantes?

Essa formulação diferenciada do conceito fundador da Geografia não expressa também uma forma de fragmentação?

Quais as implicações da fragmentação:

Reducionismo analítico? Vínculo com o empirismo?

Descrição, compreensão de temas por vezes especializados de forma fragmentada, dividida, sem articulação?

Operacionalização de análises vinculadas a ações específicas?

Produção de conhecimento explicativo sobre a realidade singular?

Ou revelação de uma particularidade do real antes não eficientemente revelada?

\section{Geografia ou Geografias?}

Retomo o título "Geografias ou Geografia? Fragmentação e Totalização" e, acrescento uma outra pergunta: para que serve a Geografia? Isso implica perguntar o que queremos com a Geografia:

\section{Explicar o mundo?}

Compreender o mundo nas suas diferenças?

Revelar fragmentos do mundo antes não revelados ou opacos?

Ena continuidade nos perguntar: Para que explicar o mundo na sua diversidade e complexidade? Para construir explicações sobre a realidade vivida e com isso ter a possibilidade de diálogo com outros campos do conhecimento? Não basta contemplá-lo? Diriam os pós-modernos, basta descrever o mundo, nas suas diferenças, a estruturação social baseada no conceito de classes sociais, por exemplo, é ultrapassada.

Para que compreender o mundo apenas nas suas diferenças? Não importam mais as desigualdades socioeconômicas? Perguntariam os geógrafos críticos. Para a Geografia a preocupação é tratar de espaços geográficos diferenciados e desiguais ${ }^{1}$ ou abordar a produção do espaço

"Haesbaert, em leitura prévia deste texto, lembra que, sob a inspiração do filósofo Bergson, podemos reconhecer "desigualdade" também como uma modalidade de diferença, mas "diferença de grau" ou de nível, quantitativa, ao contrário da "diferença em sentido estrito", sempre de caráter qualitativo e, portanto, não padronizável. 
e as desigualdades sociais? Desigualdades socioespaciais? Aqui também nos deparamos com uma questão relevante.

Particularmente, retomando Lefebvre (1986[1974]) lembramos que o espaço social traduz um conjunto de diferenças, na medida em que este é expressão do lugar, enquanto coexistência de pluralidades e similitudes. Entretanto, esta construção teórica não desconsidera o conflito entre diferentes classes sociais, gerando, no e com o espaço, desigualdades sociais/socioespaciais.

Para que revelar fragmentos do mundo antes opacos? Para contribuir com nichos de mercado ou como instrumento de resistência de povos alijados de suas condições de existência? Para cada pergunta, teremos uma forma de proceder a leitura.

A busca da compreensão da totalidade ou do processo de totalização e, neste caso, a produção do espaço geográfico (incluindo a natureza ou a segunda natureza na perspectiva dialética) enquanto produção de espaço desigual, constitui um debate contemporâneo que está presente na obra de Milton Santos e David Harvey, por exemplo. Da mesma forma em Marcelo Lopes de Souza (2016), quando se refere à Geografia como um campo epistemológico mestiço. Certamente que em cada autor é possível visualizar caminhos metodológicos diferentes. Em Souza (2016) não seria conveniente reduzir as ciências naturais às humanas ou vice-versa, em especial pela transposição de métodos de lá para cá ou daqui para lá, mas a profícua possibilidade de diálogo seria o caminho.

A compreensão das diferenças étnico-raciais, no âmbito cultural dos modos de vida e do cotidiano, sem considerar muitas vezes a relação entre questões étnico raciais e desigualdades socioeconômicas é abordada muitas vezes (esta não é uma regra geral) de forma fragmentada. Elaborada por vezes através de análises fenomenológicas, antropológicas "descritivas" ou mesmo empiristas, revela espaços opacos, mas, por vezes, não responde, explicitamente, pelas razões dessa opacidade no e com o espaço geográfico. Muitas dessas análises engajam-se nas lutas através de movimentos sociais contemporâneos; nesses casos o reconhecimento do cotidiano de opressões, desigualdades e diferenças compõe a energia para a transformação do espaço real, sem dúvida expressando uma ação geográfica. Essa ação, para ser totalizante, certamente estará em constante processo de reflexão e avanço na práxis.

Da mesma forma, na outra ponta, os estudos dos processos naturais em sua gênese e dinâmica se revelam fundamentais na perspectiva da compreensão dos fenômenos físicos, mas são insuficientes e reducionistas para explicar questões de uso, ocupação e produção de espaços geográficos de risco, por exemplo. Diante disso visualiza-se uma pluralidade temática, uma fragmentação do conceito de espaço geográfico, uma pluralidade de métodos.
Que contexto muda a rota da totalização para a pluralidade? Estapoderia estarassociadaà fragmentação? Essa perspectiva multitemática que se encaminha para a fragmentação expressa um momento histórico, a ascensão da hipermodernidade, pós-modernidade, capitalismo avançado e/ou neoliberalismo - concepções que podem guardar nas suas construções significativas diferenças. Apesar disso, essas foram agrupadas com a intensão de indicar as diferentes formas de leitura de um período que corresponde em certa medida dos anos 1960/1970 até o presente.

Nesse contexto, vivido no Brasil mais intensamente pós anos 1990, ocorrem mudanças significativas na abordagem geográfica. Tem-se visualizado nessa caminhada:

- a emergência dos estudos com enfoques culturais;

- a diversidade de temas abordados em todos os subcampos da Geografia;

- a construção conceitual diversificada de acordo com a perspectiva de abordagem. a exemplo dos sentidos diferenciados de lugar, região, território e territorialidades ou mesmo natureza e naturezas;

- a ruptura da construção de metateorias explicativas e o retorno ao estudo do singular, do diferenciado, resultante do momento atual, de valoração das diferenças e do respeito às diferenças.

Considera-se, portanto, que a fragmentação, como resultado, implicou no desmonte das metateorias de explicação mais universal, para valorizar os fragmentos do mundo. Mas isso não significa que o desejo de ainda explicar as questões geográficas contemporâneas, na perspectiva da totalidade, não sejam preocupação de muitos geógrafos, conforme já me referi: David Harvey $(1993,2016)$ Milton Santos. $(1970,1997,2000)$, exemplos de um grande número de geógrafos que buscam essa abordagem. Nesse sentido é possível verificar, contraditoriamente, que geógrafos buscam tencionar a fragmentação considerando:

- a necessidade de refletir e reconstruir o conceito de espaço geográfico, a exemplo de Milton Santos;

- a necessidade de refletir sobre a produção do espaço geográfico em articulação com as dinâmicas econômicosociais das quais é produto e produtor (Milton Santos, David Harvey);

- a necessidade de resgatar a natureza e/ou a segunda natureza para o âmbito da análise geográfica e, neste caso, propor epistemologias que permitam o diálogo das ciências naturais e sociais, sem que uma se reduza à outra. Um exemplo é a proposta de Epistemologia Mestiça de Marcelo Souza (2016) ou a proposição de Suertegaray $(2000,2001)$;

- a necessidade de não negar a cultura, mas compreender esta como uma dimensão do humano em 
processo de socialização, portanto, não separada do social, do econômico, do político, do natural, do ambiental, a exemplo das abordagens de Carlos Walter PortoGonçalves (1998, 2001), um precursor nesse diálogo;

- a necessidade de se pensar a análise geográfica com base na articulação escalar, onde seja possível compreender que a parte contém e está contida no todo em constante movimento - essa proposta de análise, derivada da análise crítica desde os anos 1970 e que enfatiza a articulação escalar se constitui em um tema de abrangente discussão;

- a necessidade de pensar os conceitos com os quais operam os geógrafos (lugar, paisagem, região, território, ambiente) em articulação, sem promover através deles a compartimentação ou fragmentação do espaço e da análise - tenho pensado nesta perspectiva considerando o espaço geográfico como uno-múltiplo, onde os conceitos nos permitem operar sob diferentes perspectivas quando da análise do espaço geográfico (Suertegaray, 2000).

- a necessidade de pensar as diferenças e as desigualdades como questões que exigem uma leitura explicativa de maior amplitude, quando tratamos de apropriação e vínculo espacial em relação a processos de expropriação ou espoliação social decorrentes de políticas hegemônicas globais analisados, por exemplo, em Milton Santos (1997), Harvey (2004, 2016), Carlos Walter Porto-Gonçalves (2001, 2006) e Moreira (2010) Enfim, é certo que se observa uma fragmentação, mas também é certo que se observa resistência e a busca de construção analítica totalizante, não só na Geografia, mas para além dela.

\section{Geografia, ciência e ação social}

0 debate entre fragmentação e totalização implica pensar sobre a Geografia e seu papel científico e social? Compreender o mundo para nele intervir? Ou intervir sem compreender o mundo?

\section{O que significa fazer Geografia hoje?}

Significa buscar uma compreensão do espaço produzido e reproduzido socialmente e suas transfigurações, conflitos e superações manifestos na materialidade do espaço e nas condições de vida de seus habitantes? Significa valorizar as meta-explicações, aquelas que permitem uma compreensão da diferenciação e da desigualdade mundial e suas expressões espaciais? Ou seja, compreender processos globais extraterritoriais, conforme Bauman (1999), ou entendê-los como processos multi ou transterritoriais que atuam no local, ou seja, entender o que vem sendo denominado de glocalismo? Para uma maior compreensão trazemos o sentido dado a multiterritorialidade por Haesbaert (2004):

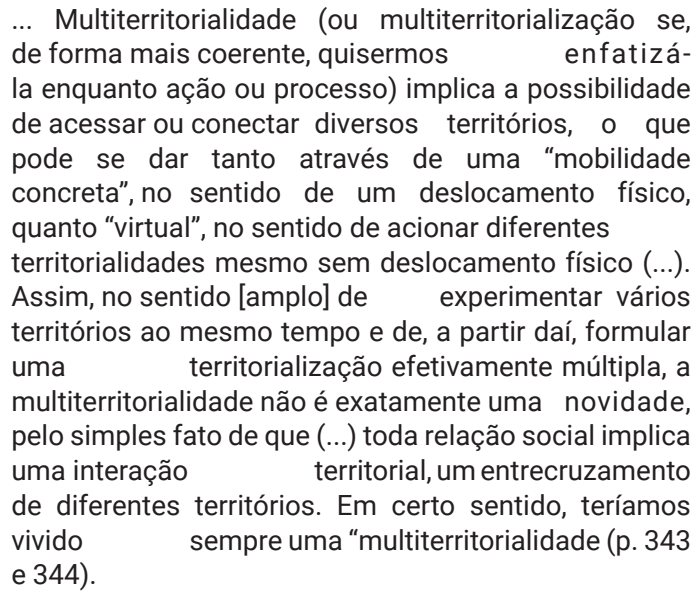

Ou a Geografia significa, hoje: valorizar ainda as formas geográficas? Numa perspectiva empirista? Ou a forma-conteúdo? 0 estudo dos processos que permitem a explicação das formas - ou significa abandonar a forma e os processos mais amplos e nos debruçarmos sobre o vivido, o cotidiano e suas representações? Ou, ainda, significa pensar os lugares enquanto expressão da forma, processos e representações na totalidade mundo? Considero que forma, processo e representações fazem parte da leitura do espaço geográfico na medida em que fazem parte de nosso processo de socialização e objetivação no espaço.

Devemos ter o cuidado, indicado por Harvey (2016) em seu livro recente, "17 contradições e o fim do capitalismo", para reconhecer que as representações não são a realidade, entre o representado e o real muitas coisas estão ocultadas (por exemplo, nos mapas). Por isso, quando pensamos dialeticamente, precisamos compreender a essência, ou seja, a mediação (a dimensão oculta), neste caso, entre o representado e o objeto de representação.

Para ir concluindo não poderia deixar de dizer que a nossa fragmentação não é só geográfica. Em relação às práticas sociais e acadêmicas, o que visualizamos?

- o individualismo acadêmico em contraponto à solidariedade;

- a negação da política e a relativização/simplificação das análises;

- o produtivismo contrariando o processo de produção e reflexão crítica.

A individualidade nos permite ser o que somos, dizer o que dizemos, ter autonomia de pensamento, ser ou não ser críticos, e isto é salutar pois valoriza o diferente. $\mathrm{E}$ sobretudo exige o respeito à singularidade do outro. Agora, o individualismo é a rejeição do outro na sua diferença, valendo os interesses de um ou de alguns sobre os interesses em relação ao outro ou aos outros. Em sendo assim verifica-se um abandono do debate acadêmico, 
uma produção desenfreada e um amordaçamento da análise crítica. Por isso finalizo com algumas questões, não tenho respostas à Geografia na sua totalidade, tenho ideias a serem discutidas. Todas estas questões estão em debate, porém, para finalizar, permitam-me trazer as proposições de Milton Santos (2000) apontadas em seu texto "O papel ativo da Geografia: um manifesto".

\section{Uma manifestação sobre o manifesto}

Milton Santos no Manifesto à Geografia (2000) indica que o papel atribuído à Geografia e a possibilidade de uma de intervenção válida dos geógrafos no processo de transformação da sociedade são interdependentes e decorrem da maneira como conceituamos a disciplina. Por conseguinte, ele propõe considerar como objeto da Geografia o espaço geográfico, não como sinônimo de território, mas território usado. Para Santos, em seu texto “O Papel Ativo da Geografia - um Manifesto" (2000), podemos ler, sintetizando a partir da aglutinação de diferentes passagens, sua proposição sobre território usado:

\begin{abstract}
Território usado é tanto resultado do processo histórico quando a base material e social de intervenções que sejam totalizadoras. É um todo complexo onde se tece uma teia de relações complementares e contraditórias. 0 território usado é a totalidade, este é a expressão do contraditório movimento entre atores hegemônicos para quem, o território é recurso e os atores não hegemônicos ou hegemonizados para quem o território é abrigo. Das diferentes combinações das ações desses atores chegase à compreensão da singularidade dos lugares, das especificidades dos lugares. (Santos,2000:103-104).
\end{abstract}

A perspectiva do território usado encaminha à compreensão do espaço banal, que se trata do:

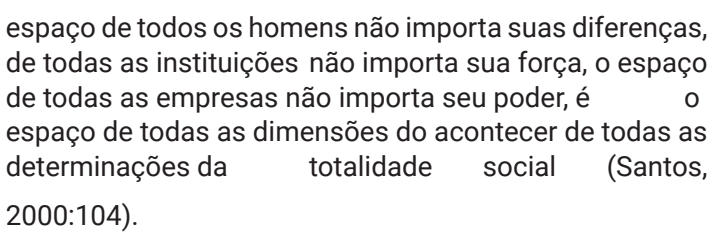

O que propõe Milton Santos? A articulação dos conceitos de lugar, formação socioespacial e o mundo (ou a totalidade). Milton Santos frisa a necessidade de unidade da Geografia através do conceito de espaço geográfico em articulação com um conjunto de conceitos que favoreçam a sua operacionalização, mas que se expressem de forma articulada e em movimento no processo de totalização. Para ele, posicionamentos parciais na Geografia frente a seu objeto promovem fragmentações e dicotomias. Estas por sua vez estão reveladas:
- na formação dos geógrafos que fragmenta o conhecimento e o trabalho;

- na formação ou na prática geográfica onde o espaço é frequentemente fragmentado: espaço político, econômico, antropológico, turístico;

Fragmentada, a Geografia não oferece uma explicação do mundo, exige cada vez mais adjetivos para explicar sua finalidade.

Prossegue Santos (2000:106): "tal fragmentação é decorrente de um lado da crescente impossibilidade socialmente gestada, de percebermos que todos os elementos agem conjuntamente". Isto se reflete, na continuidade de sua concepção, na consagrada fragmentação do ensino e especialização com vistas ao mercado de trabalho.

Sua perspectiva não pressupõe ser única. 0 conteúdo de uma Geografia compreensiva pode certamente responder a uma entre várias linhas teóricas, segundo a escolha do autor, afirma Milton Santos.

\section{Finalizando}

Porisso arrisco-me a pensar o mundo geograficamente, construindo uma perspectiva epistemológica que oriente uma reflexão-ação. Em diálogo com Milton Santos, embora promovendo uma compreensão e articulação de conceitos diferente de sua proposição, tenho buscado a compreensão do processo de totalização considerando:

- o espaço geográfico enquanto conexão da sociedade e natureza, com o cuidado de explicitar no campo teórico e sentido dado à natureza na análise;

- o espaço geográfico como uno múltiplo que pode ser operacionalizado a partir de diferentes conceitos como: lugar, paisagem, região, território, ambiente, entendidos como sendo interdependentes e constituintes de uma totalidade em movimento.

Nesse contexto valorizo os estudos da natureza na sua dimensão original (sobretudo em relação ao estudo de processos no espaço-tempo) sem, contudo, deixar de reconhecer que a natureza original, no âmbito da análise geográfica é, visivelmente, segunda natureza, ou natureza transfigurada e mais, natureza como categoria científica e filosófica sendo produto de uma construção cultural, portanto social e mutável no espaço-tempo.

Considero como fundamental a compreensão processual e histórica do fenômeno analisado buscando sua contextualização e explicações, considerando os conflitos, as contradições, a articulação com diferentes escalas, os processos mais amplos e as especificidades num dado local. Portanto, faço parte do grupo de geógrafos que busca uma compreensão a partir da totalidade, ou 
seja, busco compreender os fatos ou lugares em seu movimento contraditório, ou seja, dialético. Priorizo o movimento da sociedade em que esses fatos ou eventos se inserem, a partir da compreensão do conceito de espaço geográfico como conceito balizador da análise geográfica.

\section{Referências}

BAUMAN, Z. 1999. Globalização as Consequências Humanas. Rio de Janeiro: Zahar, 145 p.

CHAUI, M. 1992. Modernismo, Pós-Modernismo e Marxismo. In: CASTORIADIS C. et. al. A Criação Histórica. Porto Alegre: Artes e Ofícios.

DANTAS, E. W. C. (orgs). Panorama da geografia brasileira. São Paulo: Annablume, p. 91-100.

HAESBAERT, R. 2002. Territórios Alternativos. Niterói: EDUFF, São Paulo: Contexto. 186 p. 2004. O mito da desterritorialização. Rio de Janeiro: Bertrand Brasil.

HARVEY, D. A Justiça Social e a Cidade. São Paulo: Editora Hucitec, 1980.

HARVEY, D. 1993. A Condição Pós-Moderna. São Paulo: Edições Loyola. 349 p.

. 2004. Espaços de Esperança. São Paulo: Edições Loyola. 382 p. 2016. 17 contradições e o fim do capital. São Paulo: Boitempo. 2016. 297 p.

LEFEBVRE, H. 1986 (1974). La Production de l'Espace. Paris: Anthropos.

MOREIRA, R. 2010. Pensar e Ser em Geografia. São Paulo, Editora Contexto. p. 188.

PORTO-GONÇALVES, C. W. P. 1998. Os (des) caminhos do meio ambiente. São Paulo: Contexto. 148 p. . 2006. A Globalização da Natureza e a Natureza da Globalização. Rio de Janeiro: Civilização Brasileira. 461 p.

SANTOS, M. 1978. Por Uma Geografia Nova. São Paulo: Hucitec. 236 p.

. 1997. A Natureza do Espaço. Técnica e Tempo. Razão e Emoção. $2^{\circ}$ Edição. São Paulo: Hucitec. 308 p.

SANTOS M. 2000. Manifesto o Papel Ativo da Geografia. Revista Território, Rio de Janeiro, ano V, n. 9, pp. 103-109, jul. /dcz.. SOUZA, M. L. 2016. Consiliência ou bipolarização? Sobre o persistente fosso entre as ciências da natureza e as da sociedade - e o papel do geógrafo. In. SPOSITO, E. S.; SANT'ANNA NETTO, J.L. e MELAZZO, E.S. (org.) A diversidade da Geografia Brasileira. Escalas e dimensões da análise e da ação. Rio de Janeiro: Consequência Editora, 546 p., p.13 a 56. SUERTEGARAY, D. M. A. 2000. Espaço Geográfico Uno Múltiplo. In: Ambiente e Lugar no Urbano. SURTEGARAY, D. M. A VERDUM, R.; BASSO, L. A. (Orgs). Porto Alegre: Editora da UFRGS. p. 13-34.

SUERTEGARAY, D. M. A. 2004. Ambiência e Pensamento Complexo: resignific(ação) da Geografia. In, DA SILVA, D.A. e GALENO, A. Geografia ciência do complexus. Porto Alegre, Editora Sulina, p, 181- 208 (334).

2006. “Questão ambiental: produção e subordinação da natureza. ” In: DA SILVA, J. B.; LIMA, L. C.; 